\title{
Experimentation and numerical modeling of cyclic voltammetry for electrochemical micro-sized sensors under the influence of electrolyte flow
}

Adesokan, Bolaji James; Quan, Xueling; Evgrafov, A. ; Heiskanen, Arto; Boisen, Anja; Sørensen, Mads Peter

Published in:

Journal of Electroanalytical Chemistry

Link to article, DOI:

10.1016/j.jelechem.2015.12.029

Publication date:

2016

Document Version

Peer reviewed version

Link back to DTU Orbit

Citation $(A P A)$ :

Adesokan, B. J., Quan, X., Evgrafov, A., Heiskanen, A., Boisen, A., \& Sørensen, M. P. (2016). Experimentation and numerical modeling of cyclic voltammetry for electrochemical micro-sized sensors under the influence of electrolyte flow. Journal of Electroanalytical Chemistry, 763(February), 141-148.

https://doi.org/10.1016/j.jelechem.2015.12.029

\section{General rights}

Copyright and moral rights for the publications made accessible in the public portal are retained by the authors and/or other copyright owners and it is a condition of accessing publications that users recognise and abide by the legal requirements associated with these rights.

- Users may download and print one copy of any publication from the public portal for the purpose of private study or research.

- You may not further distribute the material or use it for any profit-making activity or commercial gain

- You may freely distribute the URL identifying the publication in the public portal 


\title{
Experimentation and Numerical Modeling of Cyclic Voltammetry for Electrochemical Micro-sized Sensors under the Influence of Electrolyte Flow
}

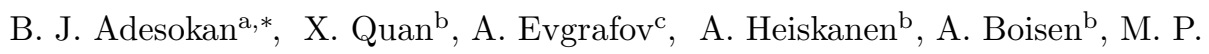 \\ Sørensen ${ }^{\mathrm{a}}$ \\ ${ }^{a}$ Department of Applied Mathematics and Computer Science, Technical University of \\ Denmark, Richard Petersens Plads, Building 324, 2800 Kgs. Lyngby, Denmark \\ ${ }^{b}$ Department of Micro and Nanotechnology, Technical University of Denmark, Building \\ 345E, Ørsteds Plads, 2800 Kgs. Lyngby, Denmark \\ ${ }^{c}$ Department of Mathematical Sciences, Norwegian University of Science and Technology, \\ Alfred Getz vei 1, Sentralbygg II 1038, Trondheim, Norway
}

\begin{abstract}
In this study, we perform experimental studies as well as simulations for cyclic voltammetry $(\mathrm{CV})$ of the redox couple $F e^{I I I}(C N)_{6}^{3-} / F e^{I I}(C N)_{6}^{4-}$ on a gold plated ECC biosensor encapsulated by a microfluidic system. We examine the effect of flow rate, scan rate, varying supporting electrolyte, exchange current density and the position of electrode on the CV measurements. The results show that at a relatively high flow $(250 \mu / L)$ and low scan rates $(50-200 \mathrm{mV} / \mathrm{s})$, the current response is limited by the convection due to quick supply of fresh ions at the electrode surface which leads to fading hysteresis of the recorded CV. However, at high scan rates $(250 \mathrm{mV} / \mathrm{s})$ and slow flow rates $(50-200 \mu / L)$, peak currents are recorded which means that mass transport is dominated by the diffusion mechanism and a quasi-steady state of $\mathrm{CV}$ is recorded. In case of insufficient supporting electrolyte, the excess charges generated during scan will lead to ohmic distortion of the electrolyte solution and consequently result into a ramping effect of the recorded CV. However, for sufficient amount of supporting electrolyte $(200 \mathrm{mM})$, the simulation results show good agreement with the experimental data. In addition, the results also show that a decrease in
\end{abstract}

\footnotetext{
${ }^{*}$ B. J. Adesokan

Email address: bojad@dtu.dk (M. P. Sørensen)
}

Preprint submitted to Journal of Electroanalytical chemistry

December 16, 2015 
exchange current density leads to a shift in the peak current of the recorded CV. Finally, the results also demonstrate that the working electrode at the center of the fluidic cell records accurate measurement than placing the electrode at the bottom of the cell. The numerical results and the experimental data show both qualitative and quantitative good agreement.

Keywords: Cyclic Voltammetry, Microelectrode Location, Nernst-Planck, Navier-Stokes, Finite Element Method

\section{Introduction}

The last decade has seen rapid progress in the use of microfabricated sensors in electrochemically charged environments for applications such as food safety, environmental monitoring, medical and health applications $[1,2,2,3,4,45,6]$.

5 These devices respond to changes in their physical, chemical and biological environments. In electrochemical systems, microfabricated sensors provide information of the chemical properties of a substance and translate them into electrical signals. This is done by coupling the devices with electroanalytical techniques. One of the most powerful analytical techniques employed for such a task is cyclic voltammetry (CV) [7, 8, 9].

Cyclic voltammetry is widely utilized as the main mode of operation for biochemical sensing devices [1, 10, 11, 12, 13] and is also useful for probing electroactive surfaces in electrical energy storage and conversion devices [14, 15, 16]. Typically CV measurements are carried out in an electrochemical system where electrodes are located in a still electrolyte solution. However, over the years rapid developments in electrochemical based sensing have inspired hydrodynamic voltammetric techniques where electrodes are placed in a fluidic cell $[1,17,18,19,20,21,22,23,24,25,26,27]$, and electrolyte solution is pumped in and out of the system. There are several advantages one can derive from such a system. For a well defined flow, the mass transport rate can be controlled quantitatively by varying the electrolyte flow rates. In addition, the introduction of convection naturally increases the rate of mass transport and this can notably 
allow one to investigate both heterogeneous and homogeneous processes as well as studying faster reaction kinetics.

The fundamental understanding of the physics involved in cyclic voltammetry necessitates the development of mathematical models that can relate system parameters such as flow rates and scan rates used in an electrochemical system [28, 29]. However, electrode kinetics is usually non-linear and CV is a transient technique implying that analytical solutions are not always available except in some limiting cases. Hence, numerical simulation is necessary. Furthermore, numerical solutions along with experimental methods allow for the effective study of parameters that characterize the output of a cyclic voltammetry measurement in more details.

Numerical solutions of the CV was first introduced by Feldberg [30, 31]. 35 Since then several other authors have numerically studied CV with diffusion as the only mode of mass transfer, see for example [32, 33, 34]. Furthermore, there is an extensive list of authors that have numerically simulated CV curves in a flowing stream, in particular the Compton's group [20, 35, 36, 37, 38]. These authors among others have employed numerical methods such as the 40 alternating direction implicit method (ADI), strongly implicit procedure (SIP), the backwards implicit method (BI) and the hopscotch algorithm [39, 40, 41] with regular meshes. Recently, the group of Unwin have studied CV recorded in Nanoscale electrodes in a walled carbon channel experimentally [42]. They have also numerially studied systems that are dominated by diffusion [43, 44] using finite element solver which eliminates the problem posed by irregular geometries. In addition, the study in their paper [45] has introduced flow into an electrochemical system for the study of linear sweep voltammetry (LSV). In this present study, we focus on simulating cyclic voltammetry coupled with electrolyte flow and examine the mechanisms involved in a microelectrochemical 50 system.

Motivated by the design and optimization of the electrode to ensure accurate CV measurement and for better characterisation of the response signal in an electrochemical system, we seek a solution method that can handle complex 
geometry which also allows for high computational flexibility and maintain the stability properties of the method deployed. We do this by simulating CV using a flexible but powerful finite element method (FEM) solver, Comsol Multiphysics [46, 47] under appropriate boundary conditions, electrode configurations in a microfluidic channel with suitable flow conditions.

This study focuses on in-depth analysis through simulation of systems parameters and variables involved in a CV measurement. In particular we investigate electrodes mounted in a microfluidic cell. We investigate the effect of flow rates, effect of scan rates, varying electrolyte concentration, changing the supporting electrolyte as well as rate constants of the reaction and compare simulations to experimental data recorded for CV measurements under different electrode configurations. We demonstrate that the location of electrodes in an electrochemical system plays a significant role while recording a CV measurement. This information will be utilized to understand the behaviour of an electrochemical system needed in designing micro electrochemical sensors with improved performance.

\section{Experimental setup of the electrochemical cantilever sensor}

The electrochemical cantilever sensor (ECC) chip presented here was fabricated by standard microfabrication processes [17]. As shown in Figure 1 , the chip has dimension $12 \mathrm{~mm} \times 11.3 \mathrm{~mm}$ and it was fabricated on a $375 \mu \mathrm{m}$ thick Si substrate. Four cantilevers were placed in the middle of the chip, each having the dimensions $100 \mu \mathrm{m}$ (width) $\times 550 \mathrm{~nm}$ (thickness) $\times 400 \mu \mathrm{m}$ (length) Each cantilever was capable of functioning as an independent working electrode (WE). The reference electrode with dimensions $100 \mu \mathrm{m} \times 200 \mu \mathrm{m}$ was placed on the right side of the cantilevers and the counter electrode with dimensions $2700 \mu \mathrm{m} \times 400 \mu \mathrm{m}$ on the left side. All the electrodes were coated using e-beam evaporation with a $2 \mathrm{~nm}$ chrome adhesion layer followed by $30 \mathrm{~nm}$ of gold. The chips were cleaned before use. They were immersed in a piranha solution for 6 min, and then rinsed thoroughly in MilliQ-water and ethanol [48]. Finally, the 
chips were blown dry with nitrogen gas and mounted in a microfluidic chamber. As shown in Figure1, the microfluidic chamber encapsulates the ECC biosensor with a volume of approximately $105 \mu \mathrm{L}$ and creates a flow path leading into the chip and through the channel past the cantilevers. The fluid enters from the side of the reference electrode and exits from the counter electrode side. There was an access to install a reference electrode in the microfluidic chamber as well. The system was connected to a syringe pump (PHD 2000 Infuse/Withdraw syringe pump, Harvard Apparatus, USA) and set the flow rates of up to $600 \mu \mathrm{L} / \mathrm{min}$.

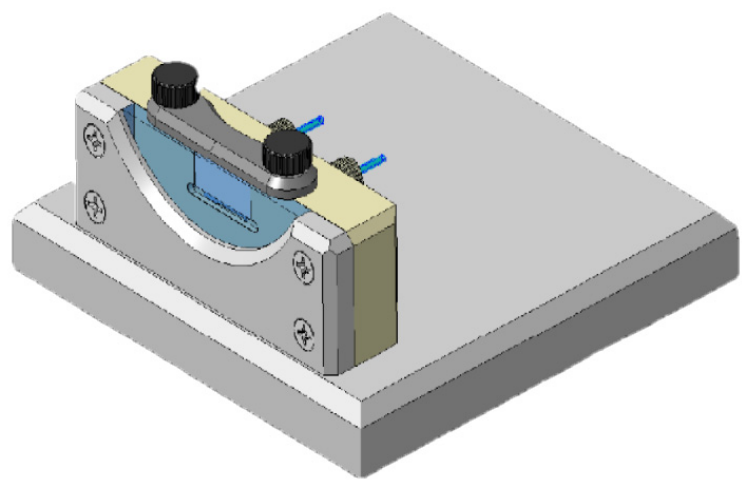

fluid flow
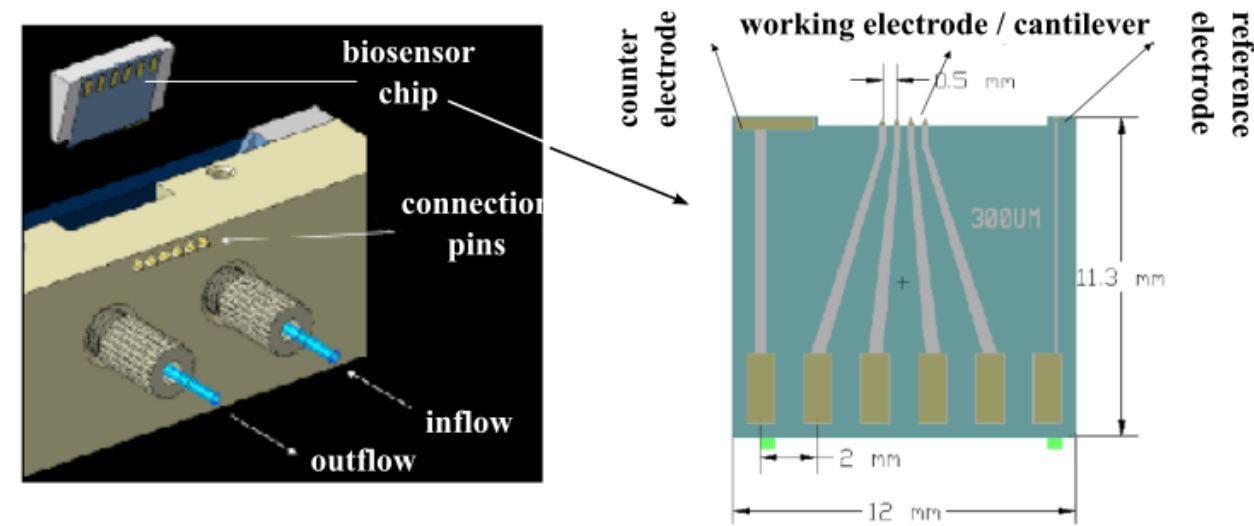

Figure 1: Fluidic cell and layout of a biosensor chip.

The electrolyte with active redox probes used in the cyclic voltammetric 
measurements consists of $200 \mathrm{mM} \mathrm{KNO}_{3}$ solutions with $2 \mathrm{mM}$ of $\mathrm{K}_{3} \mathrm{Fe}(\mathrm{CN})_{6}$ in Milli-Q water. All the chemicals were used without further purification. A DriRef-2SH Ag/ $\mathrm{AgCl}$ reference electrode (World Precision Instruments, Inc., Sarasota, FL, USA) filling with $3 \mathrm{M} \mathrm{KCl}$ solution was applied in the three electrode electrochemical cell. Cyclic voltammetry was performed using a computer controlled CHI1030 Potentiostat.

\section{Mathematical Modeling}

The current response to the applied potential at the electrode surface is proportional to the rate of electron transfer across the electrolyte-electrode interface. Consider the following electrode reaction

$$
F e^{I I I}(C N)_{6}^{3-}+e^{-} \rightleftharpoons F e^{I I}(C N)_{6}^{4-},
$$

where $F e^{I I I}(C N)_{6}^{3-}$ and $F e^{I I}(C N)_{6}^{4-}$ represent the oxidized and reduced species, respectively. When the potential is applied to the electrode, the electrolyte solution loses its equilibrium state due to the reaction at the electrode surface. The potential difference between the electrode and the adjacent electrolyte solution triggers the electrode-electron exchange in order for the system to relax to its original equilibrium state. Let $N_{j}$ denote the ionic flux of species $j$ in an electrolyte given by

$$
N_{j}=-z_{j} u_{j} F C_{j} \nabla \phi-D_{j} \nabla C_{j}+C_{j} v,
$$

where $C_{j}, D_{j}, z_{j}$ and $u_{j}$ are the ionic concentration, the diffusion constant, the charge and the mobility of the ionic species $j . F, \phi$ and $v$ represent the Faraday's constant, the electrolyte potential and the convective velocity of the solution, respectively [7, 8]. The first term in the right hand side of (2) describes the electromigration driven by the gradient of the electric potential. The second term represents diffusion due to the ionic concentration gradient within the bulk electrolyte while the last term represents convection due to the fluid flow. 
The current resulting from the motion of all charged species is computed as follows

$$
\mathbf{i}=F \sum_{j} z_{j} N_{j},
$$

and the conservation of mass for species $j$ in the bulk solution is given by

$$
\frac{\partial C_{j}}{\partial t}=-\nabla \cdot N_{j} .
$$

120

Here, we assume there is no chemical reaction within the bulk.

We shall assume that the electrolyte solution is electrically neutral except at a very thin electric double layer close to the electrode. In our analysis, we have neglected the thin double layer and assumed electroneutrality throughout 125 the solution. For an electrically neutral solution, the following holds

$$
\sum_{j} z_{j} C_{j}=0 .
$$

From equation (4) and the electroneutrality condition (5), conservation of electric current can be derived

$$
\nabla \cdot \mathbf{i}=0 .
$$

The equation for the electric potential

$$
\nabla \cdot(\kappa \nabla \phi)+F \sum_{j} z_{j} \nabla \cdot D_{j} \nabla C_{j}=0,
$$

can easily be derived from equation (6) by using the electronuetrality condition (5). Here $\kappa=F^{2} \sum_{j} z_{j}^{2} u_{j} C_{j}$ is the electrolyte conductivity. In cyclic voltammetry experiments, a supporting electrolyte e.g. $\mathrm{KNO}_{3}$ is added. The supporting electrolyte do not enter any reactions in the bulk electrolyte or on the electrodes. However, the supporting electrolyte enters the expression for $\kappa$.

Equations (4) and (77) couple the electric potential and the ionic concentrations of the system. Finally, in order to close the system, we need to determine 
the velocity field $v$ of the electrolyte. This can be done by solving the NavierStokes equations for incompressible flow,

$$
\begin{aligned}
\nabla \cdot v & =0 \\
\rho\left(\frac{\partial v}{\partial t}+v \cdot \nabla v\right) & =-\nabla p+\mu \nabla^{2} v+s_{f} .
\end{aligned}
$$

The fluid density is denoted $\rho, p$ is the pressure, $\mu$ is the dynamic viscosity and finally $s_{f}$ denotes an external force per unit volume [49, 50]. Finally, equations (4), (7), (8) and (9) must be solved with appropriate boundary conditions.

\subsection{Boundary conditions and computational domain}

In order to facilitate the numerical simulation of the micro fluidic cell depicted in Figure 1, we will restrict our computational domain to cover a volume including the cantilever electrodes and a neighborhood of the electrodes in the electrolyte. At the left boundary of the computational domain we use inflow conditions and at the right boundary we use outflow conditions, chosen as close as possible to the experimental situation. Hereby we substantially reduce the computational task in comparison to simulating the entire microfluidic cell. Specifically, we chose the computational domain in Figure2, which is small enough to facilitate the computational task yet sufficiently complex to provide comprehensive insight into the influence of the convective flow, scan rates and concentration of reactants on cyclic voltammetry for the cell shown in Figure1. In what follows, we shall specify the boundary conditions for the computational domain having length $\mathrm{L}$, width $\mathrm{W}$ and height $\mathrm{H}$. The computational domain in

155 Figure 2 encompasses the working electrode of width $w_{e}$ and length $\ell$ placed at the center of the domain but fixed to the wall of the domain anywhere between $z=0$ and $z=H$. The counter electrode is placed far down stream of the working electrode and is not shown in the figure. 


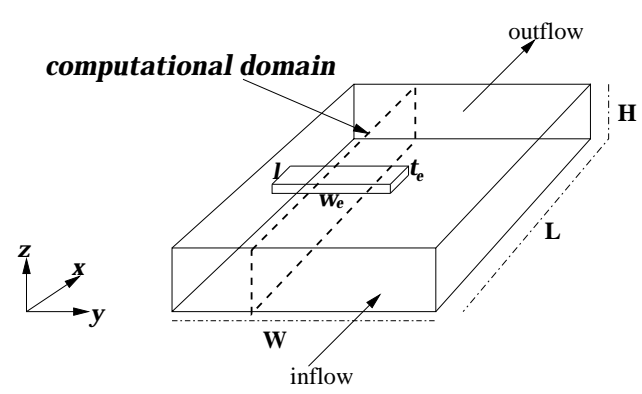

(a) centered placed electrode

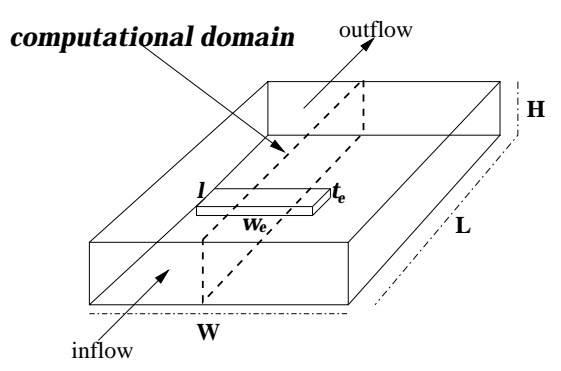

(b) bottom placed electrode

Figure 2: Schematic diagram of the computational domain of the fluidic channel with different working electrode configurations. (a) center placed, (b) bottom placed.

The reference electrode is placed upstream and the fluid flows through the microfluidic chip passing the working electrode leaving the chip at the counter electrode. The reference electrode maintains a stable and constant potential at the working electrode. There is normally no current flow passing by the reference electrode. Furthermore, we consider a cell where $H \ll W<L$ and accordingly we assume that transport of ions and fluidic motion can be considered two dimensional. This means we restrict our model to the cross sectional $x z$-plane at any point on $y$ sufficiently far from the walls at $y=0$ and $y=W$ in Figure 2.

The potential-current responses are measured at the surface of the electrode - at least within the thin layer above the electrode and hence the boundary conditions play a central role in modeling cyclic voltammetry. At the inlet we specify constant concentrations of the chemical species and a no flux boundary condition $-n \cdot N_{j}=0$ on the fluidic cell walls, where $n$ is the unit outward normal of the microfluidic chip. At the outlet of the cell we specify $D \frac{\partial C_{j}}{\partial n}=0$. At the insulating surfaces $\partial \Omega_{\text {ins }}$ there are no current flow which means that the normal current density $i_{n}$ vanish, that is

$$
i_{n}=0 \quad \text { on } \quad \partial \Omega_{\text {ins }} .
$$

In other words, from the conservation of the electric current (7) we can 
prescribe the Neumann type boundary conditions

$$
\kappa \frac{\partial \phi}{\partial n}=-z_{j} D_{j} \frac{\partial C_{j}}{\partial n} \quad \text { on } \quad \partial \Omega_{\mathrm{ins}} .
$$

However, at the electrode surface the ionic flux for each species $j$ can be modeled by the normal current density determined from electrode kinetics,viz

$$
\kappa \frac{\partial \phi}{\partial n}+z_{j} D_{j} \frac{\partial C_{j}}{\partial n}=i_{n}\left(C_{j}, \phi, v ; \phi_{a p p}\right) \quad \text { on } \quad \partial \Omega .
$$
modeled as follows,

$$
\phi_{\text {app }}(t)= \begin{cases}\phi_{\text {min }}+\nu t & \text { if } 0 \leq t \leq \mathcal{T} \\ \phi_{\text {max }}-\nu t & \text { if } \mathcal{T} \leq t \leq 2 \mathcal{T}\end{cases}
$$

where $\nu$ is the scan rate and $\mathcal{T}=\frac{\phi_{\max }-\phi_{\min }}{\nu}$ is the half cycle period.

For a cyclic voltammetry curve, one computes the total current response to the applied potential on the surface of the electrode by integrating the current density expressed in (13) at the electrode surface $\partial \Omega$

$$
i_{c v}=\int_{\partial \Omega} i_{n} d S
$$


Finally, the boundary conditions for the Navier-Stokes equations (8) and(9) are no-slip and no penetration conditions at the fluidic cell wall and at the surface of the electrode. For the inlet flow, we considered a pressure driven flow with a fully developed parabolic flow profile

$$
\begin{aligned}
& v_{x}=v_{\max }\left[1-\frac{(z-(H / 2))^{2}}{(H / 2)^{2}}\right], \\
& v_{z}=0,
\end{aligned}
$$

characterized by its maximum velocity $v_{\max }\left[53\right.$, 54]. The $v_{x}$ and $v_{z}$ are the components of the velocity along the $\mathrm{x}$ and $\mathrm{z}$ axis, respectively. $v_{\max }$ is the maximum velocity at the tip of the parabola. This approximation is valid because the flow regime is characterized by low Reynolds number and the width of the fluidic cell in the y-direction is far larger than the height H. Hence, the velocity flow is uniform across the $\mathrm{y}$-direction. The volumetric flow rate $U$ is calculated from the input velocity through

$$
U=\bar{v}_{x} H W
$$

where $W$ is the width of the fluidic cell and

$$
\bar{v}_{x}=\frac{1}{H} \int_{0}^{H} v_{x} d y=\frac{2}{3} v_{\max }
$$

is the average velocity [55]. At the outlet, we specify a constant pressure value.

\section{Numerical methods and parameters}

We solved numerically the mathematical model of the electrochemical microfluidic cell test problem using the commercial software package COMSOL Multiphysics [46, 47] on a Windows work station (Core i7 CPU, 4 cores, $2.40 \mathrm{GHz}$, 16.0GB RAM). We have simulated a $2 \mathrm{D}$ approximation to the full system in Figure 2] that is, the computational domain indicated in Figure 2, Two cases are considered with different placement of the working electrode as illustrated in 
Figure 3. In one case, the electrode is placed at the bottom of the micro fluidic cell (Figure $3 \mathrm{~b}$ ) and in the second case the electrode is placed in the centre of the cell.

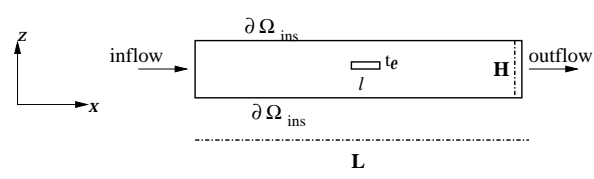

(a) center placed electrode

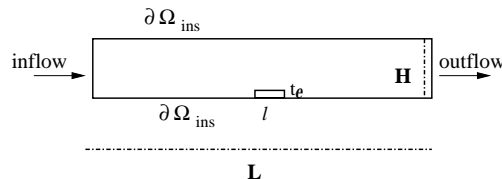

(b) bottom placed electrode

Figure 3: Computational domain with different electrode configurations.(a) center placed electrode, (b) bottom placed electrode.

We employed a two step approach in solving the coupled fluid and iontransport problem. First, we find a steady state solution to the incompressible Navier-Stokes equations.

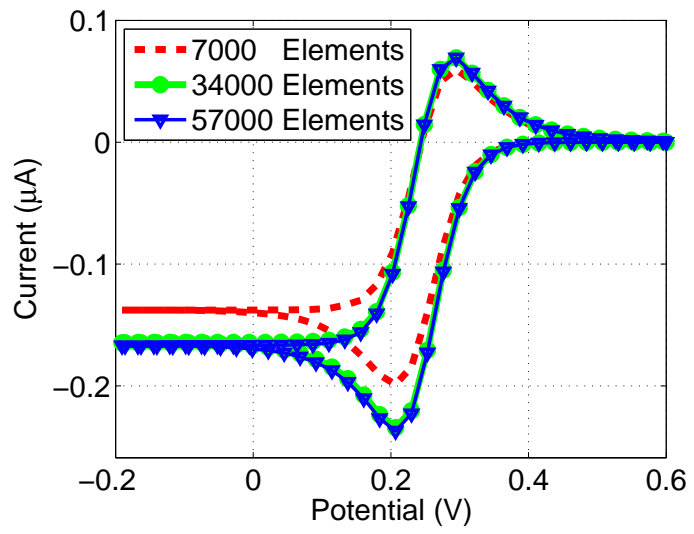

Figure 4: Simulation of cyclic voltammetry for mesh element studies. Mesh elements 34000 is sufficient for all computations. The fluidic cell geometry in a solution of $200 \mathrm{mM} \mathrm{KNO}_{3}$ with $2 \mathrm{mM}$ of $K_{3} \mathrm{Fe}(\mathrm{CN})_{6}$. The flow rate is $50 \mu / \mathrm{min}$. The scan rate is $50 \mathrm{mV} / \mathrm{s}$ and the scan direction is from $0.6 \mathrm{~V}$ to $-0.2 \mathrm{~V}$. The computations are conducted for the fluid cell geometry in Figure $3 \mathrm{a}$

The steady state velocity is then substituted into the ion transport problem. We solved the fluid flow problem by discretizing the computational domain using the linear Lagrange finite elements for the pressure field and quadratic elements 
for the velocity field. In addition, we have utilized quadratic elements for the ion transport problem [50, 47, 46].

In order to assess the accuracy of the solution method, we performed several studies based on systematic refinement of meshes until there are negligible changes in the estimated current-potential curves as documented in Figure 4 are observed. The high number of mesh elements is due to local mesh refinement around the electrode where there are large solution gradients. In order to achieve sufficient accuracy of the results we have used about 34000 elements in all of our computations. For the time integration, we have employed the implicit Euler method. Table 1 shows the parameters used throughout in the simulation.

\section{Results and Discussion}

\subsection{Assessing the parameters for the simulation}

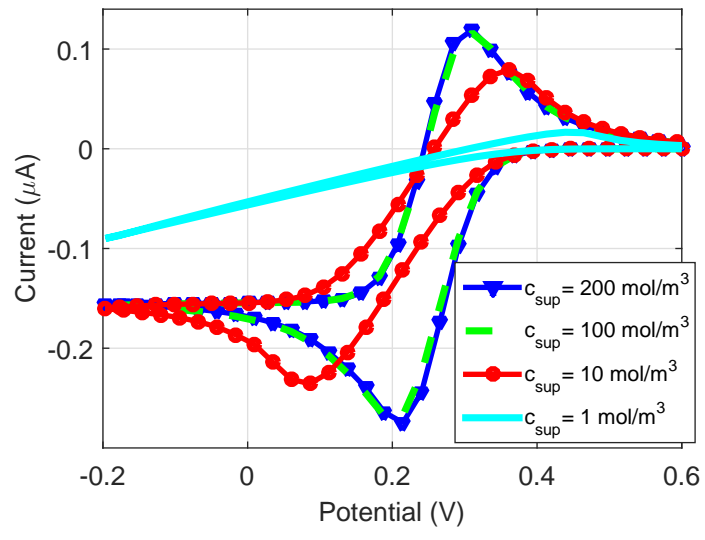

(a)

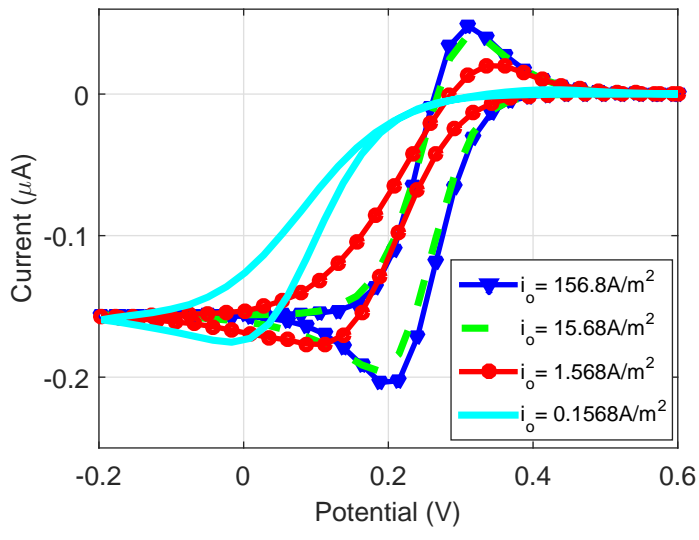

(b)

Figure 5: Simulation results showing the effect of (a) supporting electrolyte, (b) exchange current density on the cyclic voltammetry. The set-up consists of a center placed electrode in a solution of supporting electrolyte $200 \mathrm{mM} \mathrm{KNO}_{3}$ with $2 \mathrm{mM}$ of $K_{3} \mathrm{Fe}(C N)_{6}$. The flow rate is $50 \mu / \mathrm{min}$. The scan rate is $50 \mathrm{mV} / \mathrm{s}$ and the scan direction is from $0.6 \mathrm{~V}$ to $-0.2 \mathrm{~V}$. The computations are conducted for the fluid cell geometry in Figure $3 \mathrm{a}$ 
The first insight from the simulation comes from the amount of supporting electrolyte needed to be added to the electrolyte solution in the electrochemical cell when performing a cyclic voltammetry experiment. We show the effect of

$$
N_{j}=-D_{j} \nabla C_{j}+C_{j} v .
$$

We investigate the migration effect by systematically increasing the concentration of the supporting electrolyte from concentration of $1 \mathrm{~mol} / \mathrm{m}^{3}$ to concentration of $200 \mathrm{~mol} / \mathrm{m}^{3}$. The result show that at supporting electrolyte of 250 $100 \mathrm{~mol} / \mathrm{m}^{3}$, we have reached full supporting electrolyte capacity and hence the migration effect can be fully neglected. For supporting electrolytes of 1$10 \mathrm{~mol} / \mathrm{m}^{3}$, we observe a ramping effect on the observed voltammetry for the case of supporting electrolyte of $1 \mathrm{~mol} / \mathrm{m}^{3}$. We notice that the current increase linearly with the applied voltage. This is in strong contrast to exponential dependence of the current given by the Butler-Volmer relation in equation (13). This is as a result of the ohmic drop which results in uncompensated resistance in the solution. The excess charges generated during scan are not neutralized effectively by the supporting electrolyte and therefore, electric fields develops in the electrolyte solution which is strong close to the surface of the electrode. The solution electric potential affects the concentration profiles of the ionic species as well as the electron transfer kinectics as shown in Figure 5a,

Another insight from the simulation is the choice of the exchange current density which shows how the electrode kinetics affects the shape of the CV. The current density close to the electrode surface depends on the kinetic rates which 

that as the exchange current density decreases there is a shift in the peaks of the $\mathrm{CV}$ to the left of the potential scan range. For exchange current density of about $0.1568 \mathrm{~A} / \mathrm{m}^{2}$, the reaction is slow and consequently, the equilibria are not establish quick enough to result in generation of the concentrations of the

5.2. The effect of flow rates on cyclic voltammetry measurements at a microsized electrode

In Figure 6a we show experimental voltammograms at different flow rates compared to numerical simulations depicted in Figure 6b for an electrode positioned in the center of the flow chamber with $50 \mathrm{mV} / \mathrm{s}$ scan rate. As both the experiments and the simulations suggest, flow rates clearly affect the current recorded during voltammetry measurements. At flow rates of about 50 - 150 $\mu L /$ min peak currents are observed. The reason is that during the forward scan there is an accelerated electrode/electrolyte reaction and fast enough to allow have been used as in Figure 6. Comparing the results in Figure 6] and Figure 7 demonstrates that the position of the electrode impacts the shape of the recorded $\mathrm{CV}$. At the bottom of the cell the flow velocity decreases and the ion transport is dominated by diffusion leading to lower concentrations of $F e^{I I I}(C N)_{6}^{3-}$ at the 


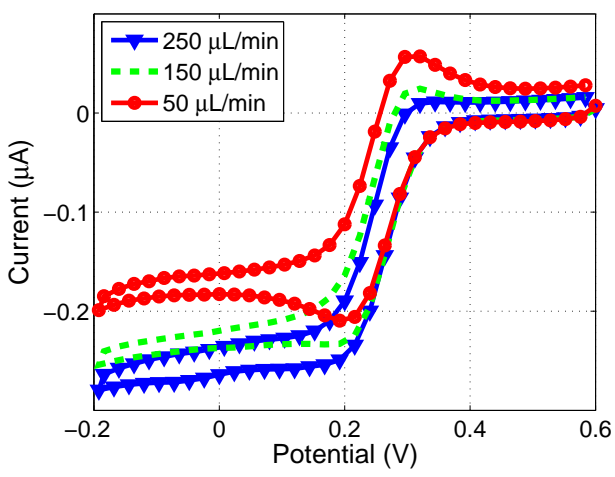

(a) experimental data

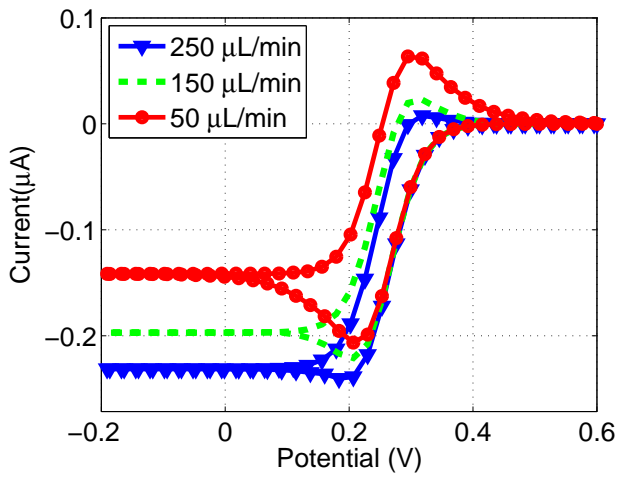

(b) simulation result

Figure 6: Comparison of a) experimental and b) simulation results of cyclic voltammograms as a function of flow rates recorded at a centre placed microelectrode in a supporting electrolyte solution of $200 \mathrm{mM} \mathrm{KNO}_{3}$ with the electrolyte solution of $2 \mathrm{mM}$ of $\mathrm{K}_{3} \mathrm{Fe}(C N)_{6}$. The flow rate is varied between $50-250 \mu \mathrm{L} / \mathrm{min}$. The scan rate is $50 \mathrm{mV} / \mathrm{s}$ and the scan direction is from $0.6 \mathrm{~V}$ to $-0.2 \mathrm{~V}$. The computations are conducted for the fluid cell geometry in Figure $3 \mathrm{a}$

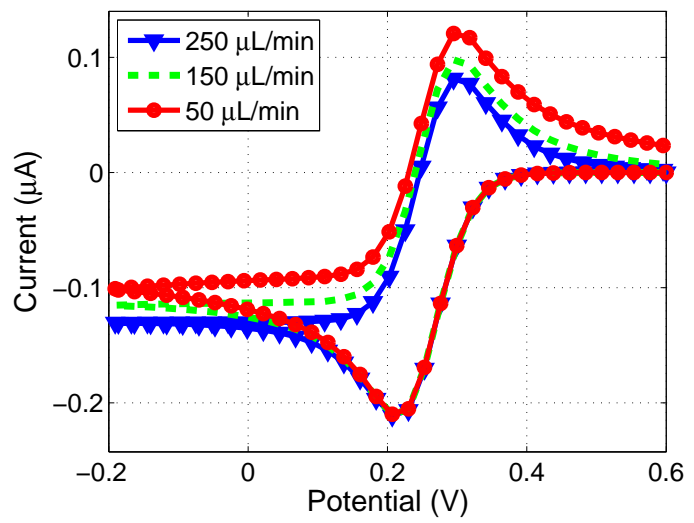

Figure 7: Simulation results showing the effect of flow rates for the working electrode placed at the bottom of the microfluidic cell. The set-up consists of supporting electrolyte solution of $200 \mathrm{mM} \mathrm{KNO} \mathrm{K}_{3}$ with the electrolyte solution of $2 \mathrm{mM}$ of $\mathrm{K}_{3} \mathrm{Fe}(\mathrm{CN})_{6}$. The flow rate is varied between $50-250 \mu \mathrm{L} / \mathrm{min}$. The scan rate is $50 \mathrm{mV} / \mathrm{s}$ and the scan direction is from $0.6 \mathrm{~V}$ to $-0.2 \mathrm{~V}$. The computations are conducted for the fluid cell geometry in Figure $3 \mathrm{~b}$ 
V. Our simulation results in Figure 7 fitted well with the previous calculations reported in [20].

At high flow rates the hysteresis of the voltammograms become less pronounced as opposed to the pure diffusion dominated mass-transport in which a quasi-steady state is obtained. This is because the electro active species are flush away very quickly such that convection dominates the mass transfer of the electro active species.

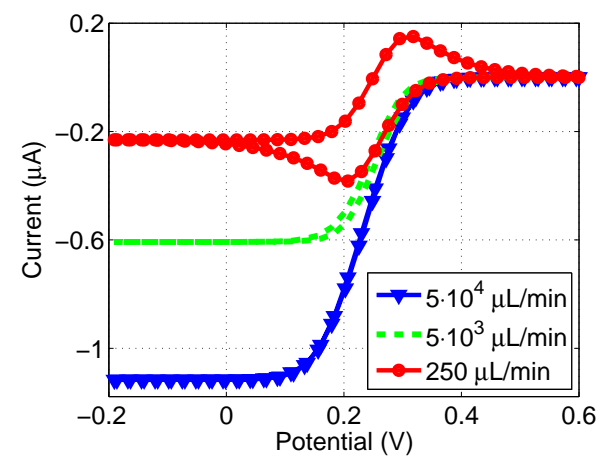

Figure 8: Simulation results for the fluid cell geometry in Figure 3a showing the effect of using extreme higher flow rates of $250-50000 \mu \mathrm{L} / \mathrm{min}$ at high scan rate of $250 \mathrm{mV} / \mathrm{s}$ and the scan direction is from $0.6 \mathrm{~V}$ to $-0.2 \mathrm{~V}$. The electrolyte solution consists of supporting electrolyte solution of $200 \mathrm{mM} \mathrm{KNO} 3$ with the solution of $2 \mathrm{mM}$ of $\mathrm{K}_{3} \mathrm{Fe}(\mathrm{CN})_{6}$.

Finally, we considered the extreme cases of flow rates at high scan rate of $250 \mathrm{mV} / \mathrm{s}$. We increased the volumetric flow rate to as high as $10^{4} \mu \mathrm{L} / \mathrm{min}$. The hysteresis of the voltammograms vanishes completely at the highest flow rate. This implies that compromise must be made as to what flow rates and scan rates are admissible depending on the object of interest in the voltammetry study.

5.3. The effect of scan rates on cyclic voltammetry measurements at a microsized electrode

Depending on the direction of scan, oxidation or reduction, it is expected that at high scan rates one records the highest current response in voltammetry. This 
is indeed observed in Figure $9 \mathrm{a}$ where we sweep the potential from $0.6 \mathrm{~V}$ to -0.2 $\mathrm{V}$ at different scan rates and at a fixed volumetric flow rate of $250 \mu \mathrm{L} / \mathrm{min}$. The associated simulation results are depicted in Figure 9b, which demonstrate fair agreement with the experimental measurements but deviates at more negative and more positive potentials. As expected, the current response increases with scan rate. At the scan rate of $250 \mathrm{mV} / \mathrm{s}$, the peak currents are observed in both directions of scan while at $50 \mathrm{mV} / \mathrm{s}$ a diminished hysteresis is recorded.

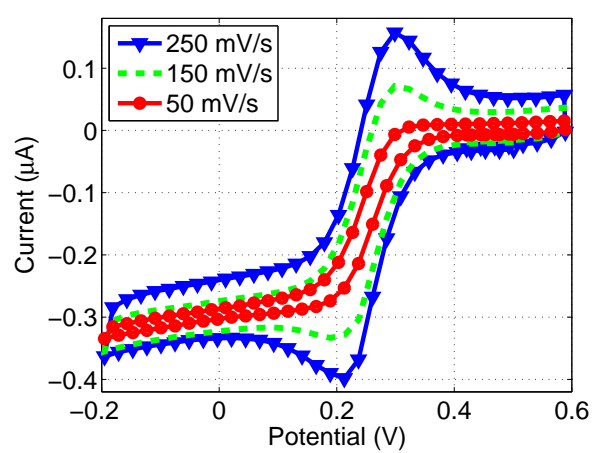

(a) experimental data

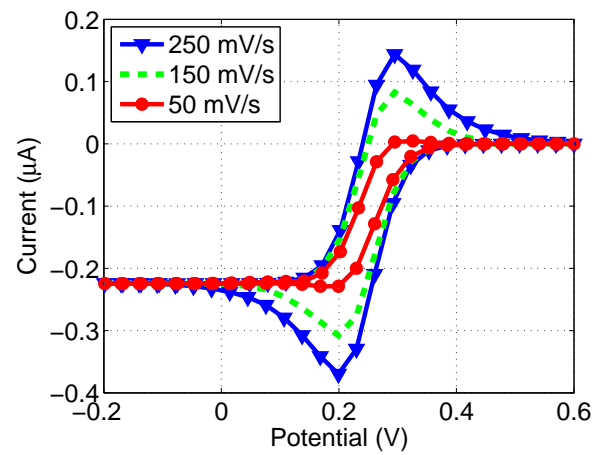

(b) simulation result

Figure 9: Comparison of a) experimental and b) simulation results of cyclic voltammograms as a function of scan rates between $50-250 \mathrm{mV} / \mathrm{s}$ recorded at a centre placed microelectrode in a solution of $200 \mathrm{mM} \mathrm{KNO} 3$ with $2 \mathrm{mM} K_{3} \mathrm{Fe}(C N)_{6}$ and flow rate of $250 \mu \mathrm{L} / \mathrm{min}$. The scan direction is from $0.6 \mathrm{~V}$ to $-0.2 \mathrm{~V}$. The computations are conducted for the fluid cell geometry in Figure $3 \mathrm{a}$

The peak at high scan rates recorded at the flow rate of $250 \mu \mathrm{L} / \mathrm{min}$ can be explained since at high scan rates surface kinetics is fast enough for electron exchange to occur before fresh electro-active ions are brought onto and the products are washed away from the electrode surface. When the potential is scanned from positive to negative potentials, the reactants lose electrons fast enough leading to the increase in current response. The products then deplete away from the electrode surface. At low scan rates, e.g $50 \mathrm{mV} / \mathrm{s}$, current is controlled mainly by diffusion and convection of the reactant to the electrode surface. However, at high flow rates, convection increases relative to diffusion 
and fresh reactants are brought to the electrode surface. In addition, because of the slow scan, electrode surface kinetics is not fast enough for the electron exchange to record a peak current and hence the narrow and flattened voltammograms as shown in Figure 9b Comparison between the experimental data and the simulation results show a very good agreement, see Figure 9a

\begin{tabular}{|l|l|l|}
\hline Parameters & Values & Definition \\
\hline$w_{e}$ & $400 \mu \mathrm{m}$ & electrode length \\
$t_{e}$ & $100 \mu \mathrm{m}$ & electrode width \\
$L$ & $550 \mathrm{~nm}$ & electrode thickness \\
$H$ & $12 \mathrm{~mm}$ & channel length \\
$E_{f}$ & $1 \mathrm{~mm}$ & channel height \\
$i_{o}$ & $0.18 \mathrm{~V}$ & formal potential \\
$c_{b u l k}$ & $156.79 \mathrm{~A} / \mathrm{m}^{2}$ & exchange current density \\
$\rho$ & $2 \mathrm{mM}$ & bulk concentration \\
$\mu$ & $997 \mathrm{~kg} / \mathrm{m}^{3}$ & fluid density \\
$P$ & $0.36 \mathrm{~m} \mathrm{~Pa}$ & dynamic viscosity \\
$T$ & $1 \mathrm{~Pa}$ & outlet pressure \\
$\nu$ & $298 \mathrm{~K}$ & room temperature \\
$D$ & $(50-250) \mathrm{mV} / \mathrm{s}$ & scan rates \\
$F$ & $7.0 \times 10^{-10} \mathrm{~m}^{2} / \mathrm{s}$ & diffusion constant \\
$R$ & $96485 \mathrm{C} / \mathrm{mol}$ & Faraday's constant \\
$\alpha_{a}, \alpha_{c}$ & $8.314 \mathrm{~J} /(\mathrm{mol} \mathrm{K})$ & gas constant \\
$u_{j}$ & 0.5 & anodic and cathodic transfer coefficients \\
$U$ & $2.529 \times 10^{-8} \mathrm{~m}^{2} / \mathrm{Vs}$ & ionic mobility \\
\hline
\end{tabular}

Table 1: Cell dimensions and other parameters used in the simulations. 


\section{Conclusions}

We have systematically presented modeling and simulation of cyclic voltam-

335 performed and compared experimental results with the simulation results. The simulation provides a valuable tool for understanding electrochemical behaviour and mechanisms of cyclic voltammetry measurement of the Ferri-Ferrocyanide redox couple. In particular, the influence of convection dominated mass trans340 port was found to be substantial under the flow rates of around $250 \mu \mathrm{L}$ for the microelectrode with width $100 \mu \mathrm{m}$ and the scan rate of $50-200 \mathrm{mV} / \mathrm{s}$. Through simulation we discover that the placement of electrodes during cyclic voltammetry under flow is very critical. The main difference between the centered placed electrode and the bottom placed electrode is the delay in the converplaced electrode. The study on varying the supporting electrolyte shows that the concentration of about $100 \mathrm{~mol} / \mathrm{m}^{3}$ is enough to offset the ohmic distortion in the electrolyte solution. Qualitative and often also quantitative agreement are found between experimental and numerical predictions for cyclic voltammetry

measurements. The mathematical model could further be developed for experimental design where the working electrode is functionalised with DNA molecules for their electrical detection. For the design and optimization of irregular electrodes, investigation of a full 3D problem might be worth investigated.

\section{Acknowledgement}

We aknowledge financial support from the Danish National Research Foundation (DNRF122) and Villum Fonden (Grant No. 9301).

\section{References}

[1] L. M. Fischer, C. Pedersen, K. Elkjær, N. N. Noeth, S. Dohn, A. Boisen, M. Tenje, Sens. Act. B: Chem. 157 (1) (2011) 321-327. 
[2] A. Subramanian, P. I. Oden, S. J. Kennel, K. B. Jacobson, R. J. Warmack, T. Thundat, M. J. Doktycz, Appl. Phys. Lett. 81 (2) (2002) 385-387.

[3] K. S. Hwang, S.-M. Lee, S. K. Kim, J. H. Lee, T. S. Kim, Annu. Rev. Anal. Chem. 2 (2009) 77-98.

[4] M. Alvarez, A. Calle, J. Tamayo, L. M. Lechuga, A. Abad, A. Montoya, Biosens. Bioelectron. 18 (56) (2003) 649 - 653.

[5] S. P. A. Fodor, R. P. Rava, X. C. Huang, A. C. Pease, C. P. Holmes, C. L. Adams, Nature 364 (1993) $555-556$.

[6] X. Quan, L. M. Fischer, A. Boisen, M. Tenje, Microelectron. Eng. 88 (8) (2011) 2379-2382.

[7] A. J. Bard, L. R. Faulkner, 2nd Edition, John Wiley \& Sons, 2001.

[8] J. Newmann, K. E. Thomas-Alyea, 3rd Edition, Wiley-Interscience, 2004.

[9] R. G. Compton, C. E. Banks, 2nd Edition, World Scientifice, 2011.

[10] S. Chevion, M. Hofmann, R. Ziegler, M. Chevion, P. P. Nawroth, Biochem. Mol. Biol. Int. 41 (2) (1997) 317-327.

375 [11] S. Chevion, M. A. Roberts, M. Chevion, Free Radical Biol. Med. 28 (6) (2000) 860-870.

[12] D. Grieshaber, R. MacKenzie, J. Voros, E. Reimhult, Sensors 8 (3) (2008) $1400-1458$.

[13] N. Cruys-Bagger, S. F. Badino, R. Tokin, M. Gontsarik, S. Fathalinejad, K. Jensen, M. D. Toscano, T. H. Sørensen, K. Borch, H. Tatsumi, P. Väljamäe, P. Westha, Enzyme Microb. Technol. 58 (2014) 68 - 74.

[14] M. Takahashi, S. Tobishima, K. Takei, Y. Sakurai, Solid State Ionics 148 (2002) 283-289.

[15] W. Sugimoto, K. Aoyama, T. Kawaguchi, Y. Murakami, Y. Takasu, J. Electroanal. Chem. 576 (2) (2005) 215-221. 
[16] X. Cheng, B. Yi, M. Han, J. Zhang, Y. Qiao, J. Yu, J. Power Sources 79 (1) (1999) 75-81.

[17] X. Quan, A. Heiskanen, Y. Sun, A. Labuda, A. Wolff, J. Jorge Dulanto, P. Grutter, M. Tenje, A. Boisen, ECS Transactions 50 (12) (2013) 77-81.

[25] R. G. Compton, P. R. Unwin, J. Electroanal. Chem 205 (12) (1986) 1 - 20.

[26] R. G. Compton, P. R. Unwin, J. Electroanal. Chem 206 (12) (1986) 57 67.

[27] K. Aoki, K. Tokuda, H. Matsuda, J. Electroanal. Chem 209 (2) (1986) 247 405

[28] R. S. Nicholson, I. Shain, Anal. Chem. 36 (4) (1964) 707-723.

[29] H. Matsuda, Y. Ayabe, Z. Electrochem 59 (1955) 494.

[30] S. W. Feldberg, J. Electroanal. Chem. 3 (1969) 199-296.

[31] M. Rudolph, D. P. Reddy, S. W. Feldberg, Anal. Chem. 66 (10) (1994) 410 $589 \mathrm{~A}-600 \mathrm{~A}$. 
[32] D. Zhao-Xiang, L. Xiang-Qin, J. Electroanal. Chem. 464 (2) (1999) 215221.

[33] M. Orlik, J. Electroanal. Chem. 575 (2) (2005) 281-286.

[34] G. Jidong, L. Ernö, Anal. Chem. 81 (1) (2009) 130-8.

[35] R. G. Compton, A. C. Fisher, R. G. Wellington, P. J. Dobson, P. A. Leigh, J. Phys. Chem. 97 (40) (1993) 10410-10415.

[36] J. A. Alden, M. A. Feldman, E. Hill, F. Prieto, M. Oyama, B. A. Coles, R. G. Compton, P. J. Dobson, P. A. Leigh, Anal. Chem. 70 (9) (1998) 1707-20.

[37] C. E. Banks, A. O. Simm, R. Bowler, K. Dawes, R. G. Compton, Anal. Chem. 77 (6) (2005) 1928-30.

[38] S. M. Matthews, G. Q. Du, A. C. Fisher, J. Solid State Electrochem. 10 (10) (2006) 817-825.

[39] M. J. Bidwell, J. A. Alden, R. G. Compton, J. Electroanal. Chem. 417 (12) (1996) $119-128$.

[40] J. A. Alden, R. G. Compton, J. Electroanal. Chem. 402 (12) (1996) 1 - 10.

[41] D. Shoup, D. Szabo, J. Electroanal. Chem. 160 (1 - 2) (1984) 1 - 17.

[42] M. E. Snowden, P. R. Unwin, J. V. Macpherson, Electrochem. Comm. 13 (2) (2011) $186-189$.

[43] P. V. Dudin, M. E. Snowden, J. V. Macpherson, P. R. Unwin, ACS Nano 5 (12) (2011) 10017-10025.

[44] M. E. Snowden, M. A. Edwards, N. C. Rudd, J. V. Macpherson, P. R. Unwin, Phys. Chem. 15 (2013) 5030-5038.

[45] E. Bitziou, M. E. Snowden, M. B. Joseph, S. J. Leigh, J. A. Covington, J. V. Macpherson, P. R. Unwin, J. Electroanal. Chem 692 (0) (2013) 72 79. 
[46] Comsol@multiphysics finite element analysis software.

URL http://wWw. comsol.com

[47] W. B. J. Zimmerman, World Scientific Publishing Co. Singapore, 2006.

${ }_{440}$ [48] X. Quan, , Ph.D. thesis, Technical University of Denmark (2013).

[49] G. Batchelor, An Introduction to fluids dynamics, Cambridge University Press, 1967.

[50] J. Fuhrmann, A. Linke, H. Langmach, Appl. Num. Maths. 61 (2011) 530553.

${ }_{445}$ [51] L. Uziel, Vol. 44 of Modern Aspects of Electrochemistry, Springer New York, New York, NY, 2009.

[52] J. Fuhrmann, H. Zhao, H. Langmach, Y. E. Seidel, Z. Jusys, R. J. Behm, Fuel Cells 11 (2011) 501-510.

[53] V. Levich, Prentice-Hall international series in the physical and chemical engineering sciences, Prentice-Hall, 1962.

[54] R. B. Bird, W. E. Stewart, E. N. Lightfoot, 2nd Edition, John Wiley \& Sons, Inc., 2006.

[55] R. Ferrigno, P. F. Brevet, H. H. Girault, J. Electroanal. Chem. 430 (1-2) (1997) 235-242.

455 [56] S. J. Konopka, B. McDuffie, Anal. Chem. 42 (14) (1970) 1741-1746. 